\title{
MODELO DE TUTORÍA ACADÉMICA CON ÉNFASIS EN LA COMUNICACIÓN PEDAGÓGICA, EN EL PROCESO FORMATIVO UNIVERSITARIO.
}

\section{Desarrollo.}

La tutoría académica en las universidades, atendiendo a las nuevas concepciones y exigencias de las transformaciones que se vienen dando, constituye en la actualidad un reto a partir del reconocimiento de la Universidad, como uno de los agentes educativos por excelencia. El hecho de perfeccionar la labor del proceso formativo universitario es una problemática latente, sin embargo, las vías utilizadas para tales propósitos, en especial, relacionadas con la tutoría académica en la República de Ecuador, aún no responden a las necesidades que demanda el profesorado universitario.

Se pretende la preparación y formación integral de un profesional reflexivo, competente, crítico, lo cual exige desarrollar el pensamiento alternativo de los mismos a través del auto aprendizaje y auto superación, desde la perspectiva de la diversidad académica, que hoy existe en las aulas.

A través del proceso modelado, se explica el movimiento y la trasformación de los componentes que deben tomarse en consideración, para perfeccionar la tutoría académica, con énfasis en la comunicación pedagógica, visualizado en los resultados del proceso formativo de los estudiantes.

Tomando como referencia el análisis efectuado, se proponen tres subsistemas para fundamentar la concepción pedagógica de tutoría académica, en el proceso formativo universitario, el significado y sentido de la comunicación pedagógica en la tutoría académica, la proxemia comunicativa en la tutoría académica y la identidad antropológica de la comunicación pedagógica en el proceso formativo universitario.

El primer subsistema, significado y sentido de la comunicación pedagógica en la tutoría académica, se define como el significado común que se construye históricamente, de naturalidad y predictibilidad, que genera un sentido de familiaridad en el proceso comunicativo, que se inicia durante la tutoría académica; el cual sienta las bases para todas las acciones, que tienen lugar entre los estudiantes y tutores, en el proceso formativo universitario.

La comunicación pedagógica, durante el inicio del proceso de tutoría académica, debe caracterizarse por buscar la presencia de una relación mutua entre el docente y los estudiantes, constituyendo un auténtico encuentro entre seres humanos que tienen una finalidad común, que consiste en la optimización de los aprendizajes y del desarrollo integral de sus personalidades. Una positiva relación 
entre docentes y estudiantes, cultiva la eficacia en el proceso docente-educativo y por ende, en su formación integral.

Constituye un proceso interactivo, en el que tutores y estudiantes asumen una posición, que dirige 0 guía su actuación en el ámbito escolar, familiar y está a su vez en correspondencia con las exigencias de la sociedad. Durante los primeros encuentros comunicativos, que se establecen en el proceso de tutoría académica, los estudiantes comienzan a manifestar actos de auto-regulación, consonantes con la determinación autónoma de metas personales; son capaces de decidir, bajo la guía del tutor, lo que es correcto desde sus razones y creación de áreas de elección personal, donde tiene lugar un proceso de interiorización de las normas de convivencia que se hacen más efectivas, en la medida de que todos los agentes educativos tributen a ese objetivo en el proceso formativo.

La tutoría académica, supone un compromiso más profundo, tanto por parte del tutor, como del estudiante, ya que abarca no sólo lo académico, sino también lo afectivo, social, profesional e institucional. Es un proceso que puede tener un carácter individual o grupal, en el cual las orientaciones valorativas y las opiniones morales y sociales, que se dan en el acto comunicativo, van a depender también de las influencias grupales. Cuando los estudiantes adquieren un sentido del compromiso de mejorar cada uno de sus actos, a partir del significado que ha tenido el compromiso personal con el tutor, la tutoría académica cumple con los objetivos y metas trazadas.

A través del significado y sentido que se le da a la comunicación, los estudiantes aprenden a expresar su opinión y a escuchar la de los demás de modo respetuoso, en este caso, ocupa un lugar importante el tipo de diálogo que se establece, como habilidad básica que facilita el proceso de formación integral de los estudiantes, en el proceso formativo universitario.

Por otro lado, asumen responsabilidades en la organización de la convivencia del grupo, con su familia, entendiendo que hay situaciones problemáticas y comprometiéndose en su mejora, por lo que se comienza a incursionar en un aprendizaje de los mecanismos de participación democrática y la realización de acuerdos. En este proceso, intervienen un conjunto de normas y valores que actúan en el grupo de estudiantes para llegar a regular su comportamiento y, al mismo tiempo, interiorizarlo, donde ocupan un lugar fundamental los estilos comunicativos en la tutoría académica, la formación de actitudes conductuales y el compromiso ético en la tutoría académica.

Cuando tiene lugar un significado y sentido de la comunicación educativa en la tutoría académica, se desarrolla en los estudiantes la disposición, simpatía y sentido hacia su formación, además de que se entrenan para desarrollar las habilidades que se requieren para la vida, como uno de los espacios formativos más importantes e integradores de las influencias educativas en la formación profesional. 
Sólo a través de una comunicación pedagógica, se logra la integración del sistema de relaciones esenciales que se establecen en la tutoría, a partir de la asesoría académica e investigativa, por parte del profesor y de otros especialistas, los servicios especializados de orientación educativa al estudiante, el proceso de extensión universitaria, por el vínculo con el entorno socio-familiar y también a través de las múltiples manifestaciones de la cultura.

En tal sentido, es considerado como primer componente de este subsistema los estilos comunicativos en la tutoría académica. Se define como el proceso donde se educan diferentes estilos de comunicación, atendiendo a las características individuales de cada estudiante, de manera que se produzca una interacción armónica y de confianza entre el tutor y el estudiante, buscando que surja la empatía como elemento condicionante para un proceso de tutoría académica.

El estilo que se utiliza entre el tutor y el estudiante, en cada una de las acciones que tienen lugar durante la tutoría académica, ocupa un lugar importante en el proceso formativo. Cada persona posee una forma singular para expresar su comportamiento, en este caso, el estilo comunicativo determina el grado de afectividad en la comunicación interpersonal a través de las relaciones que se establecen en la interacción con los demás, de allí su importancia en un proceso de tutoría académica.

Cada profesor y estudiante posee un estilo de comunicación determinado, que lo peculiariza y matiza en sus relaciones de aprendizaje e integración social, que es a su vez coherente con la personalidad, necesidades, gustos, aficiones y modo de aprendizajes; lo cual se torna decisivo en los procesos de tutorías, en que la comunicación constituye un instrumento vital para el crecimiento personal del estudiante.

Durante el proceso de tutoría académica, un estilo comunicativo adecuado entre docentes y estudiantes, va a permitir la construcción del significado en situaciones de interacción real. En la medida que el docente pueda llegar a conocer los fenómenos discursivos, estarán más cerca de describir la naturaleza formal y significativa de los estilos comunicativos, así como los valores últimos que lo sustentan.

El estilo comunicativo del docente tutor, como cualidad profesional pedagógica, su modificación y desarrollo, constituye un indicador fundamental para valorar su competencia comunicativa, que a la vez debe trasmitirla al estudiante con resultados positivos, pues en el proceso de tutoría académica, el docente se convierte en un patrón o modelo de actuación para los estudiantes.

La sensibilidad y el impacto que tiene cada estilo comunicativo en las tutorías, tiene que ver con los métodos de aprendizajes, relacionados con los comportamientos en la acción normativa, en el proceso 
didáctico, en el ambiente del aula y en las convivencias interactivas que crean los estudiantes. Los estilos de comunicación del profesor tutor, no solo deben estar centrados en el cumplimiento de las tareas docentes, sino en los actos que no afecten las relaciones entre los que participan en un proceso tutorial, es por ello que resulta importante considerar la formación de actitudes comunicativas en la tutoría académica, como segundo componente en esta modelación.

Se define como un proceso interactivo que tiene lugar entre el tutor y el estudiante con un alto potencial educativo, el cual va a ejercer un papel fundamental para la construcción de una experiencia educativa y formativa dirigida al desarrollo de valores, actitudes y habilidades socio-emocionales y éticas, que sustentan una convivencia social, donde todos participan, comparten y se desarrollan plenamente.

Constituye a su vez la valoración positiva o negativa, que el profesor y el estudiante hacen de la práctica de la conducta y la norma subjetiva, como los factores determinantes de la percepción, que tienen cada uno dentro de su contexto educativo, social y cultural.

En este proceso intervienen dos actores fundamentales: el profesor y el estudiante. El primero en su quehacer pedagógico se va enfrentando a diferentes sucesos y circunstancias, que le hacen adoptar disímiles actitudes, sin embargo, estas deben estar siempre encaminadas a mejorar el estado de ánimo del estudiante y, por consiguiente, a lograr un mayor entendimiento humano, afectivo, social y de producción intelectual.

Ante ello, es importante, que coincidan una actitud y una norma objetiva de la forma más fraterna y cordial, que no tenga preferencia ni más peso la una sobre la otra, o viceversa, de manera que durante el proceso de la tutoría académica se forme una integración positiva y se realice una acción de socialización pedagógica y cultural, con sus propias idiosincrasia y valores.

Las actitudes asumidas por el docente en la tutoría académica, deben ir acompañadas de un modelo pedagógico, que en su interrelación con el estudiante construye el saber beneficio para ambas partes. Y no en los modelos, en que el profesor da un manejo vertical de la autoridad, se cree poseedor de la verdad absoluta y con derecho a imponerla.

Por ello, las acciones en la tutoría académica, desde su génesis, apuntan a generar una conducta comprensiva, escucha activa, flexibilidad de la norma, modulación de voz suave, para que los estudiantes enfrente y tomen las decisiones autónomas, que les permita lograr actitudes de confianza, seguridad y colaborativas. Comportamientos del docente como la exclusión, señalamiento subjetivo, comparación desafiante, reprendedora, enfrentamiento verbal, no entender las necesidades 
contemporáneas de los estudiantes, poco o nada aportan a la solución del problema, que lo que necesitan es generarles confianza, seguridad e integración.

El tutor debe actuar como guía, moderador, asesor u organizador, más que como transmisor estricto de conocimientos, creando los entornos de aprendizaje adecuados que permitan cubrir los objetivos pedagógicos en cada carrera, y al mismo tiempo, lograr en el estudiante con un alto grado de motivación y una actitud activa, para que se convierta en el auténtico protagonista de su proceso de aprendizaje y formación integral.

Estamos ante una propuesta mediacional cognitiva, ya que las actitudes se desarrollan mediante un aprendizaje en un contexto de interacción, por cuanto el profesor y el estudiante intercambian, además de los conocimientos formales, diferentes valores y normas relativas al estudio, respecto a su rol estudiantil, la cualificación profesional, lo que a su vez genera una emoción y predisposición de aceptación o no, a las actividades pedagógicas de la tutoría académica. Las funciones de un tutor pueden ser entendidas como la máxima expresión del quehacer pedagógico universitario, por la posibilidad que ofrecen de integrar las áreas de investigación, docencia y extensión.

Las actitudes conductuales en el estudiante durante el proceso formativo, suelen producirse de una manera implícita y, por ello, inconsciente e involuntaria, de la misma manera pueden desarrollarse de un modo intencional y reflexivo, susceptible de ser negociada, a partir del momento en que los actores del proceso tutorial intercambian valores comunes. En este caso, juega un papel fundamental el tercer componente de esta concepción teórica y se refiere al compromiso ético en la tutoría académica.

El compromiso ético en la tutoría académica se define como un proceso que presupone el compromiso y la discreción por parte del tutor y el estudiante de todos los aspectos concernientes al proceso de comunicación que se establece entre ellos, donde debe prevalecer la prudencia y discreción, en aquellos aspectos que forman parte de la vida personal del estudiante y son depositados en la confianza del tutor, dependiendo en este caso del nivel de familiaridad alcanzado entre ambos.

Durante este proceso, es importante no ejercer dominio de ningún tipo sobre el estudiante, ni hacer uso de la relación asimétrica que mantiene con el profesorado por su diferencia con el conocimiento que profesa el segundo, con la experiencia que éste pueda tener o con las habilidades y recursos que posea para el ejercicio de su función docente, no exenta de motivación, persuasión y voluntad de ayuda.

Es importante que el tutor conozca los límites de esta tendencia a la ayuda, al convencimiento y la persuasión. Ésta es una de las formas de respeto y promoción de la autonomía del estudiante en la 
tutoría, del uso del diálogo y de la consideración a la diferencia de criterio e incluso de interpretación respecto a la veracidad o no, de lo que afirma y se propone como verdad por parte del profesorado.

Es responsabilidad del tutor en las acciones que desarrolla con los estudiantes, durante el proceso de tutoría académica, mostrarles que su punto de vista no es el único razonable, que existen otras interpretaciones o propuestas y que deben tener interés en conocerlas.

El tutor debe poseer las competencias necesarias, para abordar con los estudiantes las cuestiones socialmente controvertidas, desde posiciones de neutralidad; y no la imposición de valores desde posiciones de beligerancia. Existen modos de abordar las cuestiones controvertidas que generan aprendizaje ético y que favorecen una construcción autónoma y racional de valores en el estudiante, y otros que conducen a posiciones sólo subjetivas, sin más fundamentos.

Conviene que el tutor esté formado en cuestiones como éstas, que hoy son necesarias para evitar que su función en cualquiera de los tipos de relación considerados, sea contraria al enfoque de aprendizaje ético que debe existir en un proceso de tutoría académica. Se trata de reflexionar y de aprender un conjunto de pautas que regulen y orienten la forma de proceder, evitando que la autoridad moral y científica que pueda tener, derivada de su reconocimiento académico, no se convierta en factor que genere dependencia, pérdida de perspectiva crítica o falta de interés por conocer otras formas de aproximación y valoración.

El proceso de tutoría académica, desde una visión ética, debe caracterizarse por el respeto y cultivo de la autonomía del estudiante, la consideración del diálogo verbal y no verbal, como única forma legítima de abordar las disparidades y los conflictos del tipo que sean, y a la consideración como valor de la diferencia, no de la desigualdad.

Entre los componentes descritos existen relaciones de dependencia y subordinación que apuntan a un segundo subsistema denominado proxemia comunicativa en el proceso de tutoría académica.

Constituye un proceso que toma en cuenta en la tutoría académica el uso y percepción del espacio social, mental y personal, cómo el estudiante utiliza y responde a las relaciones espaciales en el establecimiento de grupos formales o informales. Es decir, la disposición espacial relacionada con el flujo de comunicación y las tareas cotidianas que tienen lugar en el proceso formativo, social y cultural.

Es importante la proxemia en las acciones de la tutoría académica, porque estudia las conductas no verbales relacionadas con el concepto, estructuración y utilización del espacio inmediato de los estudiantes, como indicadores de actitudes en una relación de aprendizaje y acompañamiento educativo. 
La distancia que utilizan los estudiantes y también los docentes, ya sea social o comunicativa, informa sobre posiciones e intereses y hay factores genéticos y culturales, como las jerarquías, la autoridad o el liderazgo, que determinan el tipo de relación y marcan el grado de proximidad personal.

La proxemia es un componente de la cultura, que debe ser tomado en cuenta en el proceso formativo universitario, durante la tutoría académica, pues la delimitación y el empleo del espacio tutorial varían de un sistema cultural a otro. En cada grupo se conocen las distancias más adecuadas para cada relación, esos espacios tienen significados que son compartidos o no, de manera que esos comportamientos inciden para alcanzar los objetivos educacionales.

El manejo del espacio mental y social, es fundamental en el desarrollo de la tutoría, en este proceso debe tomarse en cuenta la orientación espacial personal, de manera fundamental en el contexto de la distancia conversacional y como ésta varía de acuerdo con el sexo, el status, los roles, la cultura, entre otros aspectos. Dentro del manejo de la próxemica, entre el profesor y el estudiante, hay otros elementos, tales como los gestos, las miradas, el contacto físico. A medida que disminuye el espacio físico, suele aumentarse lo afectivo en el contacto personal, las frecuencias de las miradas y los gestos pueden volverse más expresivos. También aumenta la confianza entre estos actores, ya que pueden usar el acercamiento como comunicación interactiva, lo cual es importante en todo proceso de orientación de la tutoría.

La comunicación en el proceso de tutoría, y la forma en que el profesor interactúe, puede producir una reacción en el estudiante de forma instantánea 0 indirecta (lo que llamarían feedback 0 retroalimentación). Y la forma en que el estudiante utiliza su espacio, influye en su capacidad de relacionarse con su profesor, o de sentirse cercano o lejano.

Otros de los aspectos que influyen en la proxemia tutorial, es el nivel cultural de los estudiantes, ya que esta modifica la mentalidad y puede afectar su escala de valores. Allí entran las actitudes que tendrán ante cada relación con su entorno. Por ejemplo, la distancia que usan los profesores y estudiantes para relacionarse entre sí, cambia notablemente de una región a otra, le dan diferentes connotaciones a un gesto en particular, como la sonrisa, las miradas, los tactos (movimientos del cuerpo). Es por ello que resulta importante que exista un proceso empático en la relación tutorial, lo cual constituye el primer componente en este subsistema.

Se define como el proceso donde se genera la empatía de calidad y calidez en la tutoría académica, para lograr los objetivos de aprendizajes educativos, el estudiante y el profesor deben saber escuchar de forma interactiva y en silencio, con un nivel de receptividad, interesado, curioso y atento. Aquí 
ocupa un lugar importante la empatía no verbal, que no es otra cosa que acompañar discretamente al interlocutor con gestos y movimientos, similares a los expresados por quien hace las veces de emisor. Una vez que se ha sabido escuchar, eso le permite al profesor y al estudiante hacer una recapitulación verbal, es decir, devolver al emisor un resumen organizado de lo esencial que ha expresado, para estar seguro de que funciona un nivel adecuado de empatía.

Otro aspecto en este proceso empático, es ensenar al estudiante a expresarse con libertad, lo cual hace que surja automáticamente una predisposición abierta y disponible, para recibir lo que expresa el otro. El proceso de empatía en forma eficiente, hace que el estudiante se motive para buscar el acompañamiento docente, que necesita para mejorar su proceso de aprendizaje de manera general, así como el bienestar en la vida personal y profesional.

Para que funcione la empatía, los profesores deben comprender que los estudiantes de hoy están sobre informados, viven en un mundo icónico y virtual, por tanto, requieren ambientes de aprendizaje distintos y multidimensionales, ricos en imágenes y en palabras para cerebros que funcionan también en forma multidimensional, donde el reto del docente actual es servir de mediador de los aprendizajes. Esta comprensión permitirá lograr la transformación en la orientación de las prácticas pedagógicas, en un proceso de tutoría académica.

Es importante tomar en consideración, el choque cultural que produce incomprensión del comportamiento ajeno, lo mismo que emociones negativas, como desconfianza, incomodidad, ansiedad, preocupación, entre otros. Para superarlo, hay que comunicarse "compartiendo emociones y razonamientos" de manera que se pueda crear una relación de empatía con equilibrio emocional e intelectual.

Todo esto exige considerar la unidad entre lo individual y lo social, entre las expectativas de profesores y educandos, para lo cual es importante tomar en consideración:

- Las exigencias de carácter social en el orden formativo.

- Las aspiraciones formativas de los sujetos interactuantes.

Las exigencias sociales de carácter formativo, son declaradas en los planes de estudio y programas, emanan de los vínculos entre Universidad y sociedad. El carácter complejo y multidimensional de los problemas del mundo contemporáneo y la necesidad de una educación, que esté en armonía con las exigencias sociales, adaptada a las necesidades de cada comunidad y orientada a resolver los problemas del ser humano y de la colectividad, requiere nuevas vías educativas, más pertinentes y mejor integradas en la vida de hoy. 
Relacionado con este proceso empático de la tutoría académica, tiene lugar la dinámica afectiva espacial de la tutoría académica, como otro componente del sistema que se modela. El aula de clases es considerada un espacio multi e intercultural y social, en la cual se establece un reservorio experimental de hechos afectivos. Es algo más que un espacio de intercambios cognitivos, un espacio de construcción de actitudes y vivencias subjetivas, gestadas tanto por los estudiantes, como por los docentes, y mediados por el afecto como componente fundamental del conocer, actuar y relacionarse.

Reconocer lo afectivo de los estudiantes, está en consonancia con uno de los principios fundamentales de la pedagogía, la relación de lo afectivo y cognitivo en el proceso de enseñanza aprendizaje. Se constituye en una aproximación al proceso de formación integral que debe ejercer la tutoría académica en las universidades. Implica un paso en la comprensión de la cotidianidad universitaria y, por qué no, de la sensibilidad docente de los profesores, como una emoción fundamental en los actos de conocerse, pensar, actuar y relacionarse con los estudiantes.

Lo afectivo, es una formación intrínseca de los profesores y estudiantes, tanto a nivel intelectual como moral. La evolución histórica del hombre se ha ido llenando de significados a través de las complejas interacciones sociales, cargadas de subjetividades, de deseos, de necesidades y de realidades particulares, que han ido consolidando su referente cultural. A la vez, el estudiante en su individualidad específica, se va constituyendo como sujeto social, a través de los vínculos con la figura familiar, con el entorno de estudio y de la comunidad.

Es necesario destacar, sin embargo, que no existe un género de la sociedad ni de la Universidad, que garantice una solvencia afectiva en los estudiantes. Con cualquiera de ellos pueden obtenerse resultados humanos, especialmente si se evitan los extremos. Independientemente de su efectividad o no, durante el proceso comunicativo, este se enfrenta a numerosos obstáculos, que impiden su mejor realización, a los cuales los especialistas denominan "barreras", cuyos tipos son de carácter gnoseológicas, o sea, relativas al conocimiento, y se producen por la incultura del sujeto que debe asimilar el mensaje o emitirlo, por poca experiencia, o por ignorancia. Objetivos, que son de carácter material, no dependen de causas psicológicas y socio psicológico, las cuales están referidas a aquellas ideas que el sujeto tiene como válidas y bien fundamentadas, que actúan como elementos de bloqueo en las nuevas informaciones que le pretende transmitir.

Todas estas barreras afectan en gran medida el desarrollo de la comunicación en la tutoría académica, fundamentalmente en la que se incluyen múltiples niveles y habilidades de estudios. El docente debe evitar asumir un estilo inapropiado, porque por la vía de la desafectividad, pierde la autoridad de su saber intelectual ante su grupo de estudiantes. 
Las carencias en la afectividad por exceso o por defecto, afectan también a la conducta de aprendizajes de los estudiantes. Sin embargo, no resulta fácil encontrar relaciones de causa y efecto entre los sentimientos, afectos o pasiones con la conducta interior y exterior.

Durante el intercambio comunicativo, que se establece en el proceso de tutoría académica, los estudiantes deben expresar, no sólo lo académico, sino también sus vivencias sociales y culturales, que van más allá del ámbito estudiantil. Las apreciaciones particulares, tienen que ver con el grado de relaciones espirituales que establecen con los docentes en el aula de clase, haciendo de alguna manera tangible lo intangible, que es el afecto humano.

Desde luego, si miramos las pasiones de los profesores y de los estudiantes, por exceso o por defecto, es fácil observar problemas de conductas. Así ocurre en la falta o exceso de ira, de miedo, de tristeza, de alegría, de esperanza. La realidad personal y sentimental, además de la teórica, buscará como estrategia llevar una auténtica integración fraterna de los estudiantes y profesores. No es esta la única, ya que muchos problemas de carencias afectivas o de enfermedades psíquicas, están lejos de los objetivos educacionales de los tutores.

El quehacer académico, que propugna el estudiante por su desarrollo integral, no puede quedar excluido de este aprendizaje. Y es pues, en la cotidianidad de la docencia universitaria donde estas prácticas se deben hacer evidentes. Las instituciones de educación superior no pueden seguir exaltando el papel profesionalizante de la educación. Profesores y estudiantes están llamados a hacer de las aulas de clase un espacio para la construcción de relaciones humanas, reconociendo el afecto y la razón como acción fundamental, para el desarrollo individual, interpersonal y social, donde ocupa un lugar importante el contexto donde se desenvuelve el estudiante, de allí que este constituye otro de los componentes de este subsistema.

El contexto social de la tutoría académica, se define como el sistema de relaciones sociales, en un proceso de tutoría académica y educativa, donde se toma en consideración la naturaleza de la convivencia y el desarrollo humano del estudiante y el profesor, desde un ambiente sociocultural.

El profesor tutor debe conocer científicamente el contexto de la sociedad y sus parámetros sentimentales, que generan problemas y fenómenos de exclusión social, pero a diferencia de otras disciplinas, no en su aspecto fisiológico o psíquico, sino en su dimensión social. El hombre no nace solo, sino en el seno de una familia, de una comunidad. En una correlación social, como la de los profesores y estudiantes, existen de hecho las relaciones interpersonales, culturales, de géneros, condición social donde debido a su especificidad y multiplicidad de expresiones, siempre hay que 
estudiarlas y considerarlas para lograr los objetivos académicos y científicos, en un proceso de tutoría académica.

Las relaciones sociales, tienen diversas formas de condicionar la vida estudiantil y docente, ya que siempre pasa por la exclusión o inclusión, naturalización de razas y culturas, dominación moral y religiosa, por la exclusión política en la toma de decisiones, hasta llegar incluso a la dominación informática y económica, lo cual afecta no solo las condiciones materiales, sino espirituales e intelectuales de los estudiantes.

Todo ser humano tiene una percepción, de la situación social actual del medio en que vive, trabaja o estudia, que no solo se define por los elementos cotidianos que lo componen, sino también por el pasado, presente y futuro. De otro modo, por su genética, historia familiar, por la situación actual y las aspiraciones y visiones que tienen del futuro.

En una relación social, el medio social impone condiciones, que ni los profesores ni los estudiantes han elegido, debido a que antes hay un mundo competitivo, profesional y universitario ya constituido, sin embargo, es una oportunidad el proceso de aprendizaje en el desarrollo de una tutoría, para buscar analizar el sistema y tratar de transformarlo a favor de los objetivos estudiantiles.

También la relación social consciente, entre el profesor y el estudiante, que se produce de hecho en la tutoría académica, es una oportunidad para no reproducir malas prácticas comunicativas y mejorarlas, de manera que se logren niveles mayores de aprendizaje y de entendimiento del conocimiento humano, social, de equidad y concordia, descartando todo tipo de dominación del uno sobre el otro.

Para que existan unas buenas relaciones sociales, entre el profesor tutor y el estudiante, deben descartarse las imágenes trazadoras de futuro, acciones subjetivas, modelos de felicidad y éxitos específicos en el estudio, ya que están direccionados como fin para continuar con la inercia de dominación, no solo material, sino también simbólica, psicológica y cultural del profesor hacia los estudiantes.

Lo que procede en este caso, son las relaciones sociales de intercambio de conocimientos e información, sin egoísmo y con mucha afectividad y confianza, por ello, es de suma importancia considerar, no solo, una manifestación fenomenológica de los estados personales en los estudiantes, sino que el profesor con gran desprendimiento tiene que involucrarse en sus niveles psicológicos, antropológicos, sociales, culturales y tecnológicos. 
La identidad antropológica en la comunicación educativa constituye el tercer subsistema. Se define como el proceso que permite conocer al estudiante en el desarrollo de la tutoría académica, desde el marco de la sociedad y la cultura a la cual pertenece. En el proceso de tutoría académica, el concepto de identidad es fundamental para comprender la situación intercultural de los estudiantes, principalmente desde un punto de vista antropológico y psicológico.

Se concibe a la identidad como la conciencia que un estudiante tiene respecto a sí mismo y que lo convierte en alguien distinto a los demás. Aunque muchos de los rasgos que forman la identidad son hereditarios o innatos, el entorno ejerce influencia en la conformación de la especificidad del estudiante.

Los estudiantes en su proceso de formación durante la tutoría académica, de manera consciente e inconsciente, siempre aprehenden identidades o expresiones similares para relacionarse con sus compañeros y profesores, ya que la idea de su identidad la asocian a algo propio o de ídolos, realidad interior que se evidencia tras actitudes o comportamientos. La noción de identidad vincula la dimensión biológica del ser humano con el aspecto familiar, cultural y social.

Los comportamientos, las ideas y los sentimientos, cambian según las transformaciones del contexto familiar, institucional y social en el cual viven. Es importante definir el contexto donde se produce un encuentro de tutoría, ya que con el mismo estudiante, la interacción será diferente si tiene lugar en la Universidad, en casa de sus padres, en el parque, en los pasillos o un centro recreativo, inclusive, si está solo o en grupo.

Los estudiantes provienen de diversas y disímiles culturas y cada subcultura transporta valores e indicadores de acciones, de pensamientos y de sentimientos. A ejemplo de la cultura, la identidad está a menudo relacionada con grandes corrientes culturales y también limitadas a ellas: la procedencia territorial, el color de la piel, la religión.

La identidad constituye también un sistema de símbolos y de valores, que permite afrontar diferentes situaciones cotidianas a los estudiantes. Esto explica que frente a tal situación, un estudiante, con sus valores y su modo de pensar, de sentir y de actuar reaccionará de una manera definida. Para esto se cuenta con un repertorio de formas de pensar, sentir y de actuar que, en un momento dado, pueden combinarse.

La identidad es la síntesis que cada profesor y estudiante hacen de los valores y de los indicadores de comportamientos, transmitidos por los diferentes medios a los que pertenece. Integra esos valores y esas prescripciones, según sus características individuales y su propia trayectoria de vida, donde ocupan un lugar importante, en todo este proceso, los elementos corporales y lingüísticos. 
Los elementos corporales y lingüísticos resultan el primer componente del subsistema y están relacionados con el contexto en que se produce la comunicación intercultural, las circunstancias que modifican las características del proceso comunicativo y que están determinadas por los sucesos y eventos en marcha: conflictos, ambientes religiosos, fundamentalistas, de amistad, de solidaridad, de cooperación, incluso del territorio, porque siempre estará más cómodo el que se comunica en su propio terreno.

Todos los profesores y estudiantes, que forman una sociedad humana y, por consiguiente, un intercambio cultural de aprendizajes, se caracterizan por utilizar códigos comunicativos, que constituyen a su vez el conjunto de elementos gestuales, lingüísticos y culturales, que se combinan siguiendo ciertas reglas, para dar a conocer algo y para que funcione la comunicación durante las tutorías.

En el proceso de tutoría, donde participan el profesor y el estudiante, es decir, el emisor y receptor, o viceversa, es necesario conocer y entender culturalmente el código que cada uno utiliza en sus relaciones familiares y sociales, ya que debe lograrse un buen nivel de entendimiento y comprensión. Es decir, la decodificación del mensaje para que la comunicación no se deteriore y sea posible. La comunicación es eficaz, de calidad y eficiente, cuando se comunica en poco tiempo y lleva tres elementos en consonancia: verbo, tono y gesto.

Se trata que no sólo hay que comunicarse en la tutoría académica, compartir una relación de aprendizaje y acompañamiento educativo en un idioma conocido, sino que también hay que conocer el significado de los gestos corporales y contextuales (uso del tiempo, vestidos, orden de las cosas) para el otro, incluyendo el uso correcto de la distancia mutua al conversar o interactuar (proxemia).

También en este proceso de codificación, entre el profesor y el estudiante, existen dos variantes: el código lingüístico oral y el lingüístico escrito. En este caso es más funcional el oral por la interrelación directa y más comprensiva que se genera entre los actores de la tutoría para lograr los propósitos educacionales de formación profesional. Entre sus propósitos educacionales, los mensajes son instantáneos, se pone, de manifiesto todos los sentidos, no dependen de medios ni del tiempo, ni llegan a través de sonidos, se apoya mucho en los signos extralingüísticos, como los gestos, el énfasis, el tacto y las señales.

Los tutores deben poner atención a la significación que los estudiantes dan a sus mensajes. Hay que estudiar la lingüística y en el campo de la semiología y semiótica tenemos el signo, el texto y los códigos verbales y socio cultural, para comprender la trama social de ellos e interpretar sus situaciones sociales, desde los mensajes y en contextos determinados las relaciones de poder. 
La codificación socio cultural educativa, como segundo componente, está relacionada con el hecho de que, la comunicación intercultural es fundamental en el proceso de tutoría académica, en la medida que los medios y vías de comunicación se han expandido por todo el mundo. Nada hay más característico en los estudiantes que la pluralidad que surge de las disimilitudes, matices y diferencias que se observan en los grupos tutoriales. Estas diferencias pueden ser de índole biológica, social y cultural, incluyendo en esta última categoría a las diferencias de ethos o tendencia emocional, observada en los estudiantes de una determinada cultura.

En esta dimensión, la interculturalidad se refiere a situaciones de encuentro, contacto, o acciones conjuntas (o choque, o desencuentro, según el caso) entre profesores y estudiantes de distinta cultura, aunque muchos no estén conscientes de ello. La cultura ha de ser, por lo tanto, no una ciencia experimental en busca de leyes, sino una ciencia interpretativa en busca de significados.

La interculturalidad, en primer lugar, es un fenómeno comunicacional, puesto que se trata de culturas que están en situación de interacción comunicativa, que indicana su vez una forma particular de vida, de gente, de un período, o de un grupo humano. Donde cada una de las expresiones, en este caso de los estudiantes, va a estar ligada a la apreciación y análisis de elementos, tales como valores, costumbres, normas, estilos de vida, organización social, entre otros.

Si se define a la cultura, a partir de cómo ayuda a comprenderse entre actores de la tutoría académica, la cultura es entendida como una red, malla o entramado de sentidos, que le dan el significado a los fenómenos o eventos de la vida estudiantil, para poder interactuar socialmente, ysurge como un producto del comportamiento humano y de la vida social situados en un ambiente histórico, geográfico/climático y productivo (material e intelectual) donde ocupa un lugar importante el tipo de mediación que se establezca.

En tal sentido, la mediación cognitiva y sociológica, en la tutoría académica, resulta el tercer componente del subsistema y se define como un proceso que busca satisfacer las necesidades socio afectivas y de aprendizajes en los estudiantes, regulados por el proceso de comunicación y conduciéndolos por medio de pasos colaborativos, para ser posible llegar a un entendimiento racional.

A través de este proceso, se busca intervenir sobre las competencias cognitivas de los estudiantes, acompañándolos y orientándolos más allá de una simple interacción, más bien se pretende transformar y modificar la realidad del estudiante, a través de la reciprocidad del profesor y del medio educativo.

La mediación cognitiva es consciente, significativa, reciproca, intencional y trascendente, lo cual exige que los educandos conozcan estos procesos. No es solo reencuentro, sino acción entre dos, 
experiencia de ser y de crecimiento, valores compartidos. No hay imposición, sino acompañamiento cercano y selección de las óptimas condiciones para acceder a los aprendizajes tutoriales.

Durante la tutoría académica, es evidente que se llevan experiencias y actitudes de mediación y, más allá de la solución a los problemas interpersonales de los estudiantes, lo que se promueve es un modelo de convivencia más íntimo. Resolverlos conflictos relacionados con la transgresión de las normas de convivencia, con barreras didácticas y metodológicas, con situaciones que desagraden o parezcan injustas, malos tratos o cualquier tipo de problemas que suelan ocurrir.

La mediación cognitiva y sociológica en la tutoría académica, desde una relación de dependencia y subordinación con los elementos corporales lingüísticos y la codificación sociocultural educativa, promueve la comunicación y el entendimiento entre las partes durante la tutoría académica. Por otro lado, el hecho de tomarse en cuenta en este aspecto la concepción y diseño de estrategias dirigidas a la tutoría académica, permite enriquecer las normas disciplinarias de estudio, ofreciendo alternativas, a través del diálogo franco y efectivo, evitando la pérdida de relaciones interesantes y la vivencia de sentimientos de desencuentro, que influyan de forma negativa en el proceso tutorial.

Un acto de mediación del profesor con el estudiante, propone la búsqueda creativa de soluciones y la evaluación de las mismas por las partes, para llegar a un acuerdo. Estos han de ser equilibrados, específicos, posibles. También se suele dedicar un tiempo a consensuar algún procedimiento de revisión y seguimiento del proceso de tutoría.

Un proceso realmente educativo de la tutoría académica, y no meramente instructivo, sólo tiene lugar cuando las relaciones entre el docente y los estudiantes no son únicamente de transmisión de información, sino de intercambio socio cultural, de actitudes afectivas, de interacción e influencias mutuas, cuando se establece una adecuada percepción y comprensión entre los protagonistas del hecho tutorial.

En la dinámica del sistema modelado, se producen cambios constantes para llegar a la autenticidad comunicativa en la tutoría académica, como aspiración final, a la vez que se producen reajustes como un todo. Estos cambios están dados por la homeostasis que tiene lugar en el sistema, existe una armonía dinámica entre cada uno de sus componentes, que le permiten adaptase y alcanzar un equilibrio interno, frente a los cambios externos que se pueden ir dando para llegar al proceso de tutoría académica que se aspira.

Por otro lado, se da la recursividad al existir independencia y coherencia entre cada uno de sus componentes y subsistemas. Es decir, se pueden identificar sus límites, comprenderlos, explicarlos e 
interpretarlos, lo cual da la posibilidad de establecer causas y consecuencias entre el proceso modelado de la tutoría académica, con énfasis en la comunicación pedagógica, en el proceso formativo universitario.

La sinergia del sistema modelado, se expresa en una nueva cualidad que lo caracteriza la autenticidad comunicativa pedagógica en la tutoría académica, como una cualidad indispensable en el proceso formativo universitario, que expresa la orientación positiva, activa y transformadora de un sujeto hacia sí mismo, las demás personas y los contextos con las que interactúa, a través del proceso de comunicación que se establece durante la tutoría académica, partiendo de la integración de lo individual, social y profesional y que se manifiesta en la congruencia de los planos internos y externos de su actuar cotidiano.

En consecuencia, con la definición constituyen indicadores de esta cualidad:

Conocimiento e identificación de las aspiraciones a lograr en lo individual y socio profesional. Compromiso con la autransformación y autoeducación.

Actuación en correspondencia con los valores, intereses y necesidades de la sociedad, en la que se realice su individualidad.

$\checkmark \quad$ Manifestar coherencia entre pensar, sentir, decir y actuar en los diferentes contextos (familiar, educacional, comunitario, político-social, profesional, etc.)

Este proceso educativo aspira del estudiante no solo a auto conocerse como persona y conocer lo que se espera de él como profesional y ser humano integral, sino también que existan las posibilidades reales para que experimente, vivencie, reflexione, exprese sus sentimientos, desarrolle su pensamiento crítico, en resumen, que pueda llevar a cabo su actuación ante la vida, en la que se manifieste la conjunción armónica entre ser, deber ser y poder ser.

La autenticidad, tal como se enfoca en esta concepción, debe incluir, al mismo tiempo, la posibilidad del sujeto para insertarse en los diferentes contextos donde actúa, asumir como suya la responsabilidad de ser parte del proceso educativo y de transformar y auto transformarse, de implicarse personalmente con lo que hace o va a hacer, incluyendo su propio desarrollo como personalidad.

Esta cualidad no se educa de forma espontánea, debe ser concebida a través de un proceso educativo, en el cual desempeña un papel importante la coherencia que se establezca entre las disímiles influencias educativas que el sujeto reciba, sin subestimarlo en su rol de sujeto del proceso educativo. En su educación desempeñan un papel importante los tipos de interacciones que se 
establecen y desarrollan, entre todos los agentes socializadores del proceso educativo, en especial para el caso que se valora, entre el tutor y el estudiante.

El tutor, está llamado a desempeñar un rol fundamental en la educación de esta cualidad, teniendo en cuenta las posibilidades de interactuar con el estudiante a un nivel más individual. En estas interacciones, lo cognitivo y lo afectivo se deben conjugar en un nivel tal, que propicie la autorregulación individual y consciente del educando .El tutor en su rol de guía, orientador y mediador del proceso educativo, en su función de aglutinador de las influencias educativas debe considerar las intenciones de sus tutorados, posibilitando que estos de forma protagónica se proyecten en la consecución de sus necesidades, expectativas y aspiraciones.

La comprensión por parte del tutor, de que el estudiante no es un simple objeto en el proceso formativo, sino un sujeto responsable con espacio al diálogo y la polémica, que construye aprendizajes y crece, a partir de las diversas interacciones que establece y desarrolla con todos los factores del proceso educativo, constituye un requisito indispensable del proceso formativo universitario.

La concepción teórica que se presenta, no puede entenderse como la simple sumatoria de los subsistemas de orden inferior que los conforman. El sistema que se propone y modela debe interpretarse y comprenderse en su totalidad, pues desde su organización interna emergen las relaciones que distinguen su dinámica.

A partir del análisis de los diferentes sistemas de relaciones que se manifiestan en la concepción argumentada, se distinguen las regularidades siguientes:

- La concepción pedagógica de tutoría académica, con énfasis en la comunicación educativa, en el proceso formativo universitario, es expresión del proceso de solución de las insuficiencias en la comunicación tutor estudiante a un nuevo nivel cualitativo de la contradicción entre la comunicación con carácter verticalista y el carácter transactivo de la misma en el proceso formativo del estudiante universitario, la cual en su lógica interna impulsa una relación de coordinación entre el significado y sentido de la tutoría académica en el proceso formativo, la proxemia comunicativa en el proceso de tutoría académica y la identidad antropológica de la comunicación educativa.

- Los subsistemas significado y sentido de la tutoría académica en el proceso formativo, la proxemia comunicativa en el proceso de tutoría académica y la identidad antropológica de la comunicación educativa, tienen relaciones de coordinación, dado que son cualidades del mismo nivel jerárquico que se presentan simultáneamente, durante todo el proceso de tutoría académica, en el proceso formativo universitario. 
- Dentro de la relación recíproca de los subsistemas significado y sentido de la tutoría académica en el proceso formativo, la proxemia comunicativa en el proceso de tutoría académica y la identidad antropológica de la comunicación educativa, existe una relación de interdependencia, dado que la comunicación, durante el proceso de tutoría académica, requiere de una proyección donde estén presentes los elementos corporales lingüísticos, lo sociocultural y lo sociológico, lo cual le confiere a la concepción su cualidad de autenticidad comunicativa pedagógica en la tutoría académica.

\section{BIBLIOGRAFÍA}

- Amayuela Mora Georgina (2004). Estrategia didáctica para la transposición de la cultura psicológica sobre la simetría funcional comunicativa al contexto formativo universitario. Tesis presentada en opción al grado científico de Doctor en Ciencias Pedagógicas. Universidad de Camagüey, Cuba.

- Águila Carralero Alisvech. (2006) Metodología para el desarrollo de la competencia comunicativa desde lo paralingüístico en estudiantes de la carrera de derecho. Tesis presentada en opción al grado científico de Doctor en Ciencias Pedagógicas. Universidad de Camagüey, Cuba.

- Feregrimo, H. La tutoría como soporte para el estudiante externo a la ciudad capital. [cd-rom] H. Feregrino[ et. al] .2006 Ciudad de la Habana: Evento Pedagogía 2006. [Consulta: 2006].

- Fernández González, A. Comunicación Educativa. A. M. Fernández González...[ et. al].-Ciudad de la Habana: Editorial Pueblo y Educación, 2002.

- Fernández Ríos, L. (2005) Autovaloración como formación de la personalidad .En: Pensando en la personalidad./ L. Fernández Rius.- La Habana: Editorial Félix Varela. 2005 T.2.

- González Rey F. (1989) La personalidad, su educación y desarrollo./ F. González Rey, A. Mittjans.- La Habana: Editorial Pueblo y Educación.

- Valdivia, C. (1998). La orientación y la tutoría en los centros educativos: Cuestionario de evaluación y análisis tutorial. España: Ediciones Mensajero.

- Ehuletche,A; Santángelo, H. (2000). El diseño de propuestas pedagógicas en la enseñanza no presencial, con soporte de Nuevas Tecnologías y Redes de Comunicación. Pixel Bit. Revista de Medios y Educación. № 15 Junio- 2000. Universidad de Sevilla. Secretaría de Recursos Audiovisuales y Nuevas Tecnologías. 